\title{
Electrochemical aspects of grinding media-mineral interaction on sulphide flotation
}

\author{
M K YELLOJI RAO and $\mathrm{K}$ A NATARAJAN \\ Department of Metallurgy, Indian Institute of Science, Bangalore 560012 , India
}

\begin{abstract}
Galvanic interaction between electrically conducting minerals may affect the mineral surface and influence their flotabilities. The metallographic examinations as well as hardness measurements have been made with grinding media. Rest potential, combination potential, galvanic current and polarization studies were made to understand the probable electrochemical interaction between grinding media and chalcopyrite. The galvanic contact lowered the flotability of chalcopyrite. AES and ESCA indicated that galvanic coupling of chalcopyrite with grinding media resulted in the formation of oxy-hydroxide species of iron on the chalcopyrite surface. Scanning electron microscopy was used to study the surface morphological changes on the grinding media due to galvanic interaction with chalcopyrite.
\end{abstract}

Keywords. Grinding media; chalcopyrite; flotation; galvanic interaction.

\section{Introduction}

Wet grinding in ball mills is an essential step before any flotation process. In ore grinding, grinding balls come in contact with freshly generated mineral surfaces in the presence of oxygen and an aqueous electrolyte. Galvanic interactions involving grinding media and mineral surfaces could thus take place in a mill with the active steel ball material undergoing corrosion while the relative nobier sulphide minerals serving as cathode surfaces. Such electrochemical interactions, while grinding, could not only lead to increased ball wear but would also affect the surface property of the ground mineral whose flotation response would thus be influenced. For example, the effect of different types of grinding on the flotation of sphalerite, galena and pyrrhotite has been demonstrated (Rey and Formanek 1960; Thornton 1973; Adam and Iwasaki 1984). The role of electrochemical interaction between grinding mediamineral and mineral-mineral, and its effect on flotation have been studied in the past (Natarajan and Iwasaki 1973; Pavlica and Iwasaki 1982; Learmont and Iwasaki 1984; Nakazawa and Iwasaki 1985, 1986).

In this paper, the role of grinding media-mineral interaction on the flotation response of chalcopyrite mineral has been discussed. Physical metallurgy of the balls with respect to metallography and hardness was also studied. The electrochemical behaviour of the chalcopyrite and grinding media was studied in detail using rest potential, combination potential, galvanic current and polarization measurements. The nature of the sulphide surface after contacting with the grinding media in the presence and absence of oxygen has been examined through Auger electron spectroscopy (AES) and X-ray photoelectron spectroscopy (ESCA). Also, scanning electron microscopic studies were carried out to understand the surface morphological changes on the grinding media after galvanic interaction with chalcopyrite.

\section{Experimental}

The hyper steel grinding media as well as the chalcopyrite mineral samples used in this study were supplied by $\mathrm{M} / \mathrm{s}$ Chitradurga Copper Company Limited, 
Chitradurga, Karnataka. The ball sample analysed $1.6 \% \mathrm{C}, 1.1 \% \mathrm{Si}, 1.8 \% \mathrm{Cr}$, $1.2 \% \mathrm{Mn}, 0.06 \% \mathrm{P}, 0.06 \% \mathrm{~S}$, the rest being iron. Discs of $5 \mathrm{~mm}$ thickness were cut out from fresh as well as worn-out industrial balls and thoroughly polished and etched ( $5 \%$ NITAL) before microscopic examination. Rockwell ' $\mathrm{C}$ ' hardness was measured at different points in the ball. Specimen preparations for metallographic examinations, hardness measurements, SEM examinations and for electrochemical measurements are illustrated in figure 1 (Perez 1982).

Carefully handpicked chalcopyrite mineral specimens, analysing $29.8 \%$ copper, were used in contact and flotation studies. Electrochemical measurements such as electrode potential, combination potential and galvanic current besides polarization studies were made using the chalcopyrite mineral and grinding media material. The above materials were fashioned in the form of electrodes and mounted to the bottom tip of a perspex tube using epoxy resin. A saturated calomel electrode (SCE) was used as reference electrode in all the electrochemical measurements. For polarization studies and galvanic current measurements a corrosion measurement console (EG \& G model 351) was used.

To study the effect of grinding media-mineral interaction on flotation, a crucible made out of the grinding media was used. One gram of freshly ground chalcopyrite mineral $(-200+300$ mesh) was taken in the crucible along with $10 \mathrm{ml}$ of $0.5 \mathrm{M}$ sodium chloride solution at $\mathrm{pH} 10.5$ for this purpose. The chalcopyrite mineral after such a contact treatment for different periods of time (up to 4 hours) was conditioned for 5 minutes with a collector (sodium isopropyl xanthate) before Hallimond tube flotation. A nitrogen flow rate of $25 \mathrm{ml} / \mathrm{min}$ was used in all the flotation tests.

The amount of iron dissolved from the grinding media in the presence and absence of mineral contact under different experimental conditions was also estimated spectrophotometrically.

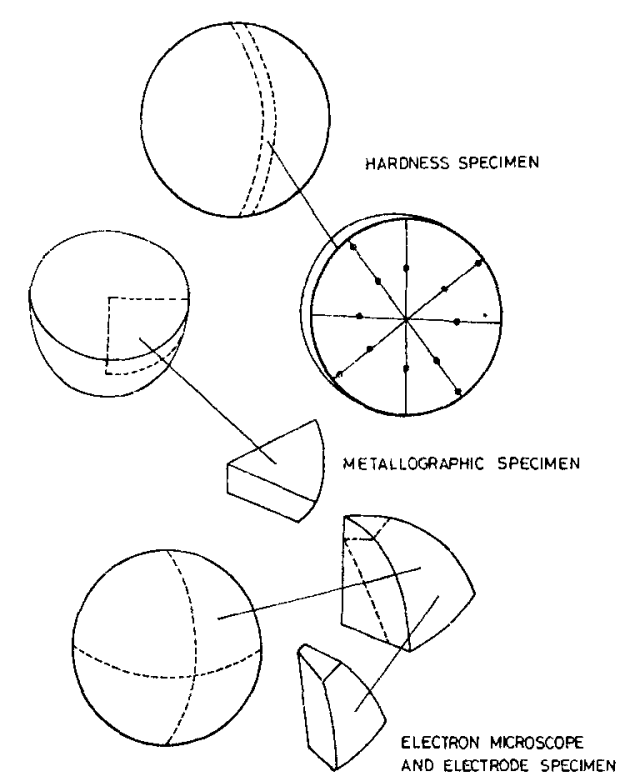

Figure 1. Cutting of the grinding media balls to obtain specimens for metallography, hardiness, microscopy and electrode. 
Surface analysis techniques such as AES and ESCA were used to characterize the surface films formed on chalcopyrite after galvanic interaction with the grinding media under different aeration conditions. A spectrometer (VG Scientific ESCA-3, Mark II) using magnesium $\mathrm{K}_{x} \mathrm{X}$-rays was used for this purpose. All the surface analyses were carried out immediately after the contact experiments.

The surface morphology of the grinding media before and after galvanic interaction with chalcopyrite under an oxygenated atmosphere was examined with a scanning electron microscope (Cambridge Instruments, model S-150).

\section{Results and discussion}

\subsection{Physical metallury of the grindiny media}

Metallographic examination of the fresh grinding media revealed a pearlitic structure from the case to the core as could be seen from figure 2. Metallographic structures of the worn-out balls after grinding were also found to be similar. Thus, there appears to be no significant change in the microstructure during the grinding operation, which involves forces of impact, abrasion and corrosion.

The hardness of the balls was measured to be $R_{\mathrm{r}} 37 \cdot 25$. Here again, there was no significant change in the hardness from the case to the core. While cutting the ball for preparing specimens for metallographic and electrochemical studies, casting defects such as blow holes were observed in many specimens.

\subsection{Electrochemical measurements}

The steady-state electrode potentials for the chalcopyrite and the grinding media under oxygen and nitrogen aeration conditions in a $0.5 \mathrm{M}$ sodium chloride solution maintained at $\mathrm{pH} 10.5$ are shown in table 1 . The rest potentials tend to increase in the positive direction in the presence of oxygen. The chalcopyrite mineral was found to be nobler than the grinding media.

The combination potential as well as the galvanic current in the chalcopyritegrinding media combination were observed to be $-210 \mathrm{mV}$ and $6.82 \mu \mathrm{A}$ in an oxygenated atmosphere and $-260 \mathrm{mV}$ and $6.02 \mu \mathrm{A}$ in a nitrogen atmosphere respectively. An increase could be observed in the galvanic current value in the presence of oxygen. Due to the galvanic contact, an electrochemical cell is formed because of which a mixed potential is established. The active material among the couple will assume anodic position while the nobler one will serve as the cathode. Active material dissolution will be the anodic reaction while oxygen reduction will take place on the surface of the nobler (cathode) one.

Results of potentiodynamic studies at a scanning rate of $1 \mathrm{mV} / \mathrm{sec}$ for chalcopyrite and grinding media under different aeration conditions are illustrated in figures 3 and 4 . The cathodic polarization curves were extended upto $-1.0 \mathrm{~V}$ whereas for anodic polarization it was extended up to $+1.0 \mathrm{~V}$ (vs SCE). In the case of chalcopyrite, a passivation behaviour around $+700 \mathrm{mV}$ and a transpassive behaviour was observed around $+800 \mathrm{mV}$, irrespective of the aeration type employed. Also, in the cathodic polarization, the current reached a limiting value around a potential of $-700 \mathrm{mV}$, the magnitude being more for a deoxygenated system. For the grinding media, limiting current values were attained during anodic polarization at potentials 

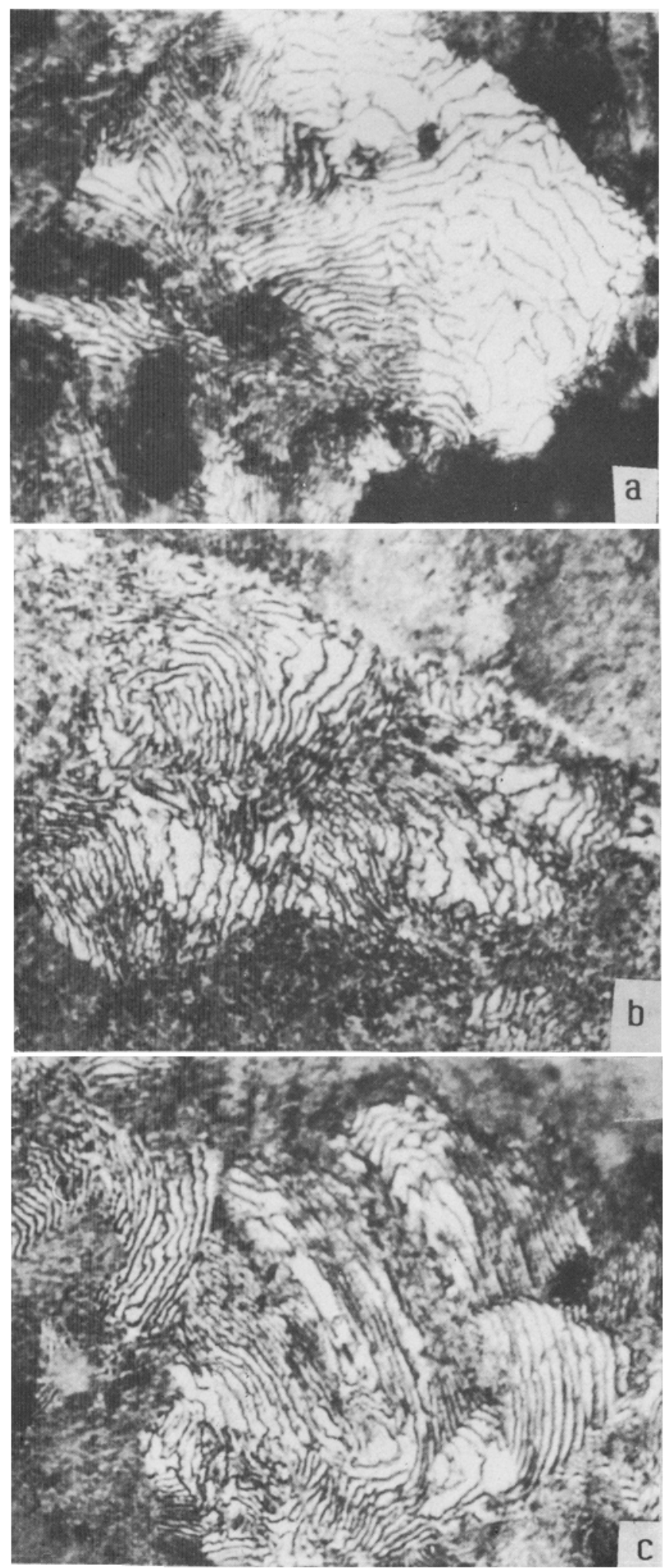

Figure 2. Microstructures of the grinding media. a. Surface; b. at $R / 2$; c. centre. 
Table 1. Steady state rest potentials for chalcopyrite and grinding media in $0.5 \mathrm{M}$ sodium chloride solution maintained at $\mathrm{pH} 10.5$.

\begin{tabular}{lcc}
\hline & \multicolumn{2}{c}{ Rest potential, $\mathrm{mV}$ (SCE) } \\
\cline { 2 - 3 } & $\mathrm{N}_{2}$ & $\mathrm{O}_{2}$ \\
\hline Chalcopyrite & -100 & -85 \\
Grinding media & -500 & -450 \\
\hline
\end{tabular}

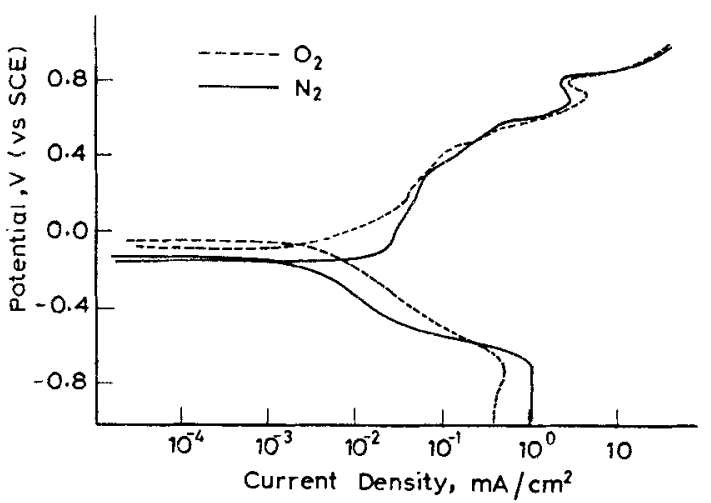

Figure 3. Polarization curves for chalcopyrite under different aeration conditions.

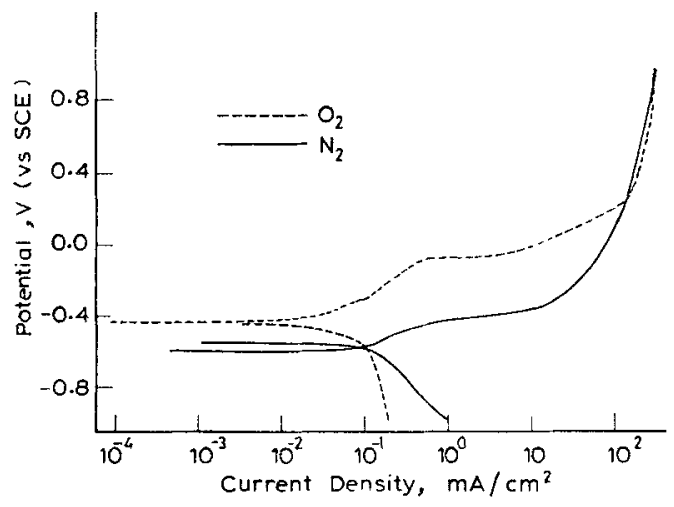

Figure 4. Polarization curves for grinding media under different aeration conditions.

above $+230 \mathrm{mV}$, irrespective of the type of aeration. During cathodic polarization under an oxygenated atmosphere, a limiting current was observed after a potential of about $-600 \mathrm{mV}$. No limiting current region could be observed under a deoxygenated atmosphere with the grinding media.

A combination polarization diagram depicting the cathodic part involving chalcopyrite and the anodic part involving grinding media is shown in figure 5 . The mixed potentials attained under oxygen and nitrogen aeration conditions are also indicated in the figure. This diagram is closer to the real electrochemical conditions existing inside a mill, in that the ground chalcopyrite mineral acts cathodically to the corroding ball material. 


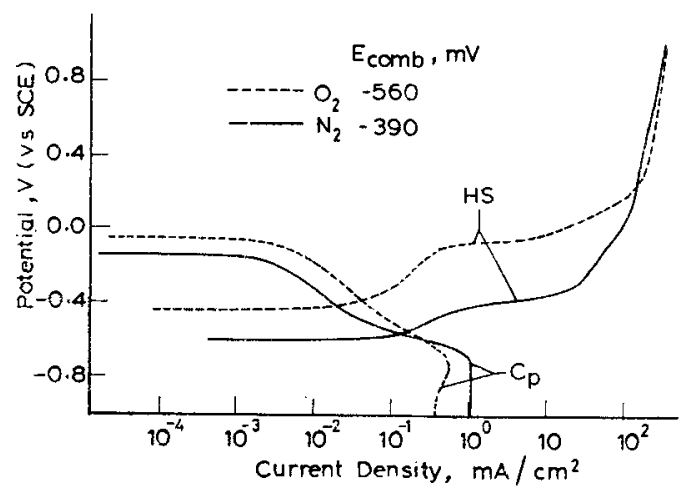

Figure 5. Combined polarization curves for chalcopyrite $\left(C_{p}\right.$; cathodic) and hyper steel grinding media (HS; anodic).

\subsection{Flotation tests}

After establishing the electrochemical behaviour of chalcopyrite and the grinding media, flotation tests were carried out to study the effect of galvanic interaction on the flotation of chalcopyrite. In the first place, the minimum concentration of the collector needed to obtain maximum recovery of chalcopyrite was established. It was found that a collector concentration of $10^{-5} \mathrm{M}$ yielded about $96 \%$ recovery and a further increase in the collector addition did not improve the recovery. Based on these results, a collector concentration of $10^{-5} \mathrm{M}$ was used in subsequent flotation tests. The flotation recovery of chalcopyrite after contact with the grinding media for different periods of time in the presence and absence of oxygen is illustrated in figure 6 . The flotation recoveries decreased as the contact period was increased. Also, the presence of oxygen during the galvanic contact significantly decreased the flotation recovery compared to a deoxygenated condition.

It should be possible to predict the possible electrochemical reactions when chalcopyrite is contacted with the grinding media. Chalcopyrite exhibits cathodic behaviour when contacted with the grinding media. Under the above conditions, anodic oxidation of grinding media leading to the formation of iron species is expected.

$$
\mathrm{Fe} \rightarrow \mathrm{Fe}^{2+}+2 e
$$

The ferrous ions so dissolved from the anode would be subsequently oxidized to the ferric form and further precipitated as their oxy-hydroxides at the alkaline $\mathrm{pH}$ of the medium. The presence of oxygen would accelerate the anodic reaction, since it serves as an essential reactant for the cathodic reaction.

$$
\mathrm{O}_{2}+2 \mathrm{H}_{2} \mathrm{O}+4 e \rightarrow 4 \mathrm{OH}^{-} \text {. }
$$

The amount of iron dissolved from the grinding media in the presence and absence of chalcopyrite under different aeration conditions is indicated in figure 7 as a function of contact period. It could be readily seen from the figure that the iron dissolution is enhanced in the presence of chalcopyrite as well as oxygen. Iron dissolution from grinding media takes place to a lesser extent in the absence of oxygen obviously due to the absence of a prominent cathodic reaction. 


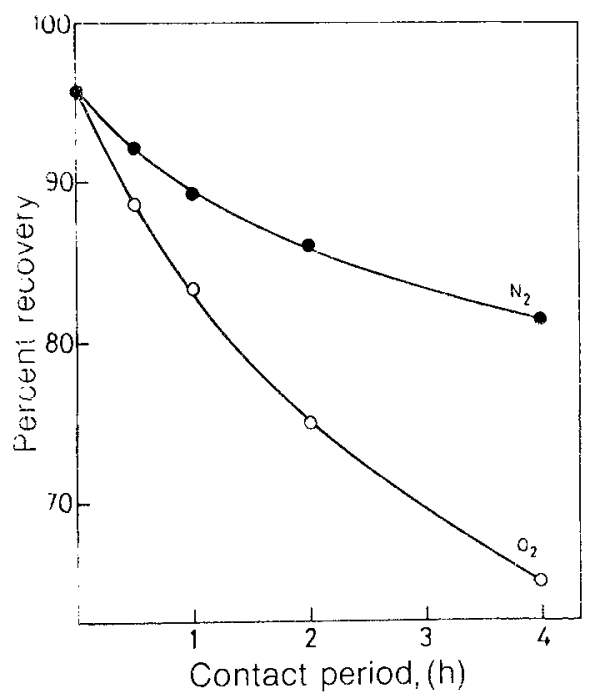

Figure 6. Flotation recovery of chalcopyrite as a function of its contact period with grinding media.

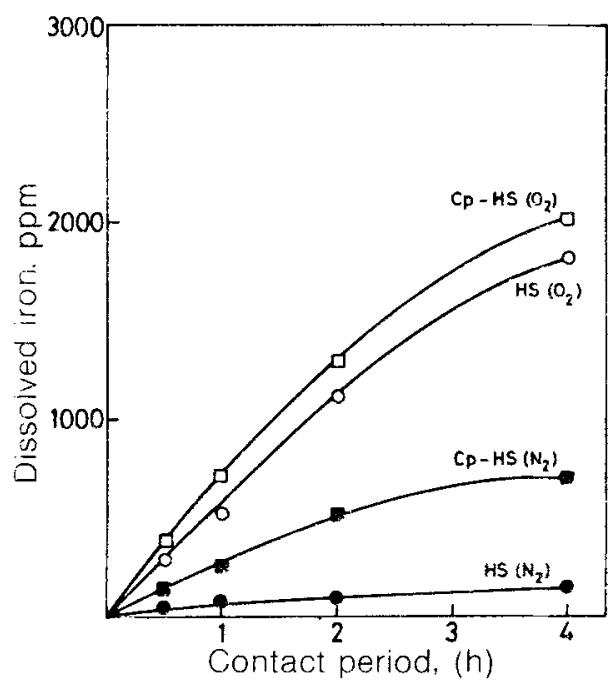

Figure 7. Amount of iron dissolved from grinding media in the presence and absence of chalcopyrite.

The influence of chalcopyrite-grinding media galvanic contact on the flotation recovery of chalcopyrite could be seen in the light of the results shown in figure 6 . There appears to be a direct relation between the amount of iron dissolved from the anode and the flotability of chalcopyrite.

\subsection{Surface analysis}

To investigate the possible reasons behind the decrease in the flotability of chalcopyrite after galvanic interaction with the grinding media, AES and ESCA studies were carried out. The samples used for the purpose were; 
(a) fresh chalcopyrite sample; [ $\mathrm{CuFeS}_{2}$-dry],

(b) chalcopyrite interacted with hyper steel grinding media in a nitrogen atmosphere; $\left[\mathrm{CuFeS}_{2}-\mathrm{HS}\left(\mathrm{N}_{2}\right)\right]$ and

(c) same as in (b) but in an oxygenated atmosphere; $\left[\mathrm{CuFeS}_{2}-\mathrm{HS}\left(\mathrm{O}_{2}\right)\right]$.

Initial survey scans showed peaks for carbon, oxygen, copper, iron, sulphur, sodium and chlorine (for samples other than fresh). The carbon peak is attributed to the general contamination whereas sodium and chlorine peaks are derived from the electrolyte used in the contact studies. The binding energies for the various elements for all the samples are given in table 2. The respective spectra for $\mathrm{Cu}(2 p), \mathrm{Fe}(2 p)$, and $\mathrm{S}(2 p)$ are given in figures 8 to 10 . The binding energy of $\mathrm{Cu}(2 p)$ as well as $\mathrm{Cu}(\mathrm{LMM})$

Table 2. Binding energies and $\mathrm{Cu}: \mathrm{Fe}$ ratios derived from AES and ESCA spectra.

\begin{tabular}{lccc}
\hline & \multicolumn{3}{c}{ Binding energy (eV) } \\
\cline { 2 - 4 } Elements & $\mathrm{CuFeS}_{2}-$ dry & $\mathrm{CuFeS}_{2}-\mathrm{HS}\left(\mathrm{N}_{2}\right) \mathrm{CuFeS}_{2}-\mathrm{HS}\left(\mathrm{O}_{2}\right)$ \\
\hline $\mathrm{Cu}(2 p)$ & 932.7 & 932.9 & 932.6 \\
$\mathrm{Fe}(2 p)$ & 707.2 & 709.5 & 709.6 \\
$\mathrm{~S}(2 p)$ & 162.3 & 162.1 & 162.0 \\
$\mathrm{Cu}: \mathrm{Fe}$ & 1.45 & 1.58 & 2.7 \\
\hline
\end{tabular}

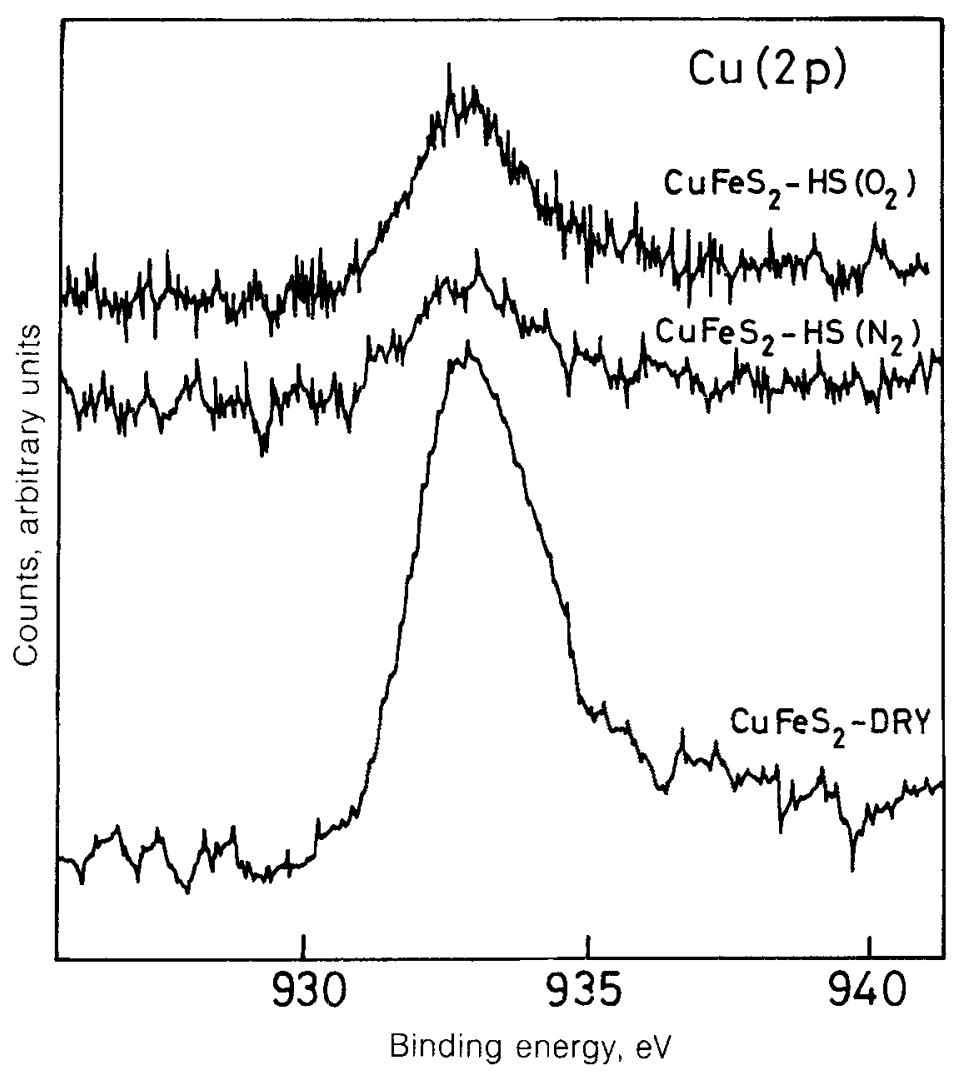

Figure 8. XPS spectra for $\mathrm{Cu}(2 p)$ for different chalcopyrite samples. 


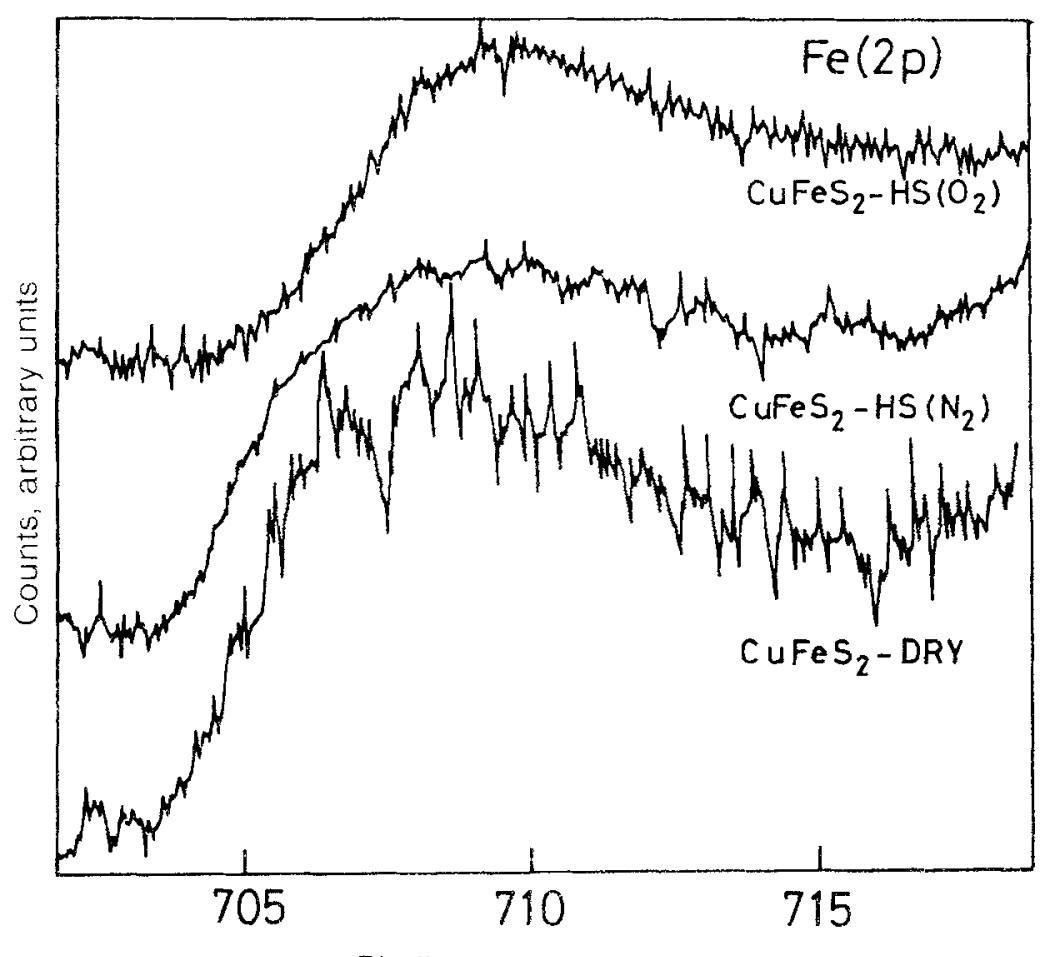

Binding energy, eV

Figure 9. XPS spectra for $\mathrm{Fe}(2 p)$ for different chalcopyrite samples.

Auger line given in the table do agree with the expected value (Wagner 1984) and suggest that the copper is in the near metallic state as $\mathrm{CuS}$ and $\mathrm{Cu}_{2} \mathrm{~S}$. Similarly, in the untreated sample, the $\mathrm{Fe}(2 p)$ peak at $706 \mathrm{eV}$ corresponds to that of FeS nearly. Correspondingly, the sulphide sulphur peak is observed at $161-162 \mathrm{eV}$ as expected. However, the $\mathrm{Fe}(2 p)$ region in the galvanically interacted samples exhibits peaks in the range of $709-710 \mathrm{eV}$ in addition to the peak due to FeS. Correspondingly, $\mathrm{O}(1 \mathrm{~s})$ peaks were observed in the $530.7-531.0 \mathrm{eV}$ region, identifiable as due to oxyhydroxides. Neither of the treated chalcopyrite samples exhibited peak due to $S(2 p)$ in the region $167-168 \mathrm{eV}$, which is characteristic of $\mathrm{SO}_{4}^{2-}$ ion, clearly indicating the species formed due to the galvanic interaction are only oxides and hydroxides of iron and not a sulphate. It could also be observed from table 2 that the $\mathrm{Cu}: \mathrm{Fe}$ ratio is higher for treated samples compared to fresh chalcopyrite. Such an observation could be attributed to the presence of iron oxide and hydroxide species on the chalcopyrite surface which has been kept in contact previously with grinding media, the amount of iron species being present in larger amounts when oxygen was present during galvanic contact.

The surface morphology of the grinding media before and after galvanic contact with chalcopyrite for $4 \mathrm{~h}$ in the presence of oxygen in a solution of $0.5 \mathrm{M}$ sodium chloride at $\mathrm{pH} 10.5$ as observed under a SEM is illustrated in figure 11. The formation of precipitates on the grinding media surface after contact with chalcopyrite could be clearly seen. These observed precipitates are essentially corrosion products (oxy-hydroxide species of iron) from the grinding media. 


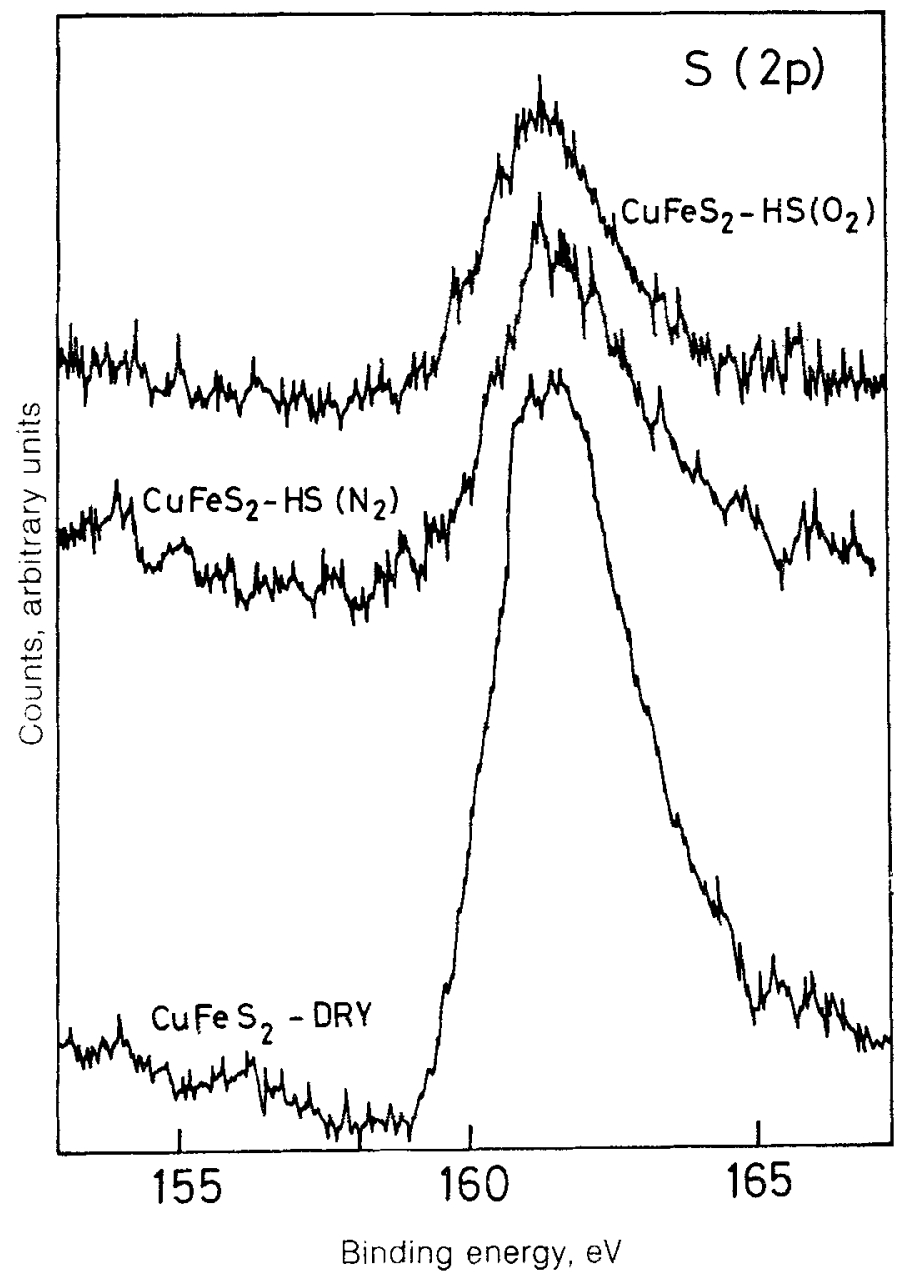

Figure 10. XPS spectra for $S(2 p)$ for different chalcopyrite samples.

Based on the above results, it becomes clear that due to the galvanic interaction between chalcopyrite and grinding media, an initial formation of iron species by the anodic corrosion of grinding media would occur. Because of subsequent adsorption or deposition of these species on the mineral surfaces, the flotation response of chalcopyrite is affected.

\section{Conclusions}

Some of the important conclusions based on this study are summarized below:

(i) No change in the microstructure of the balls could be observed before and after grinding.

(ii) Galvanic interaction between the chalcopyrite and the grinding media influences the flotation of chalcopyrite. Prior contact of chalcopyrite with the grinding media significantly lowers its flotability. The presence of oxygen during such contact further brings down the flotability of chalcopyrite. 


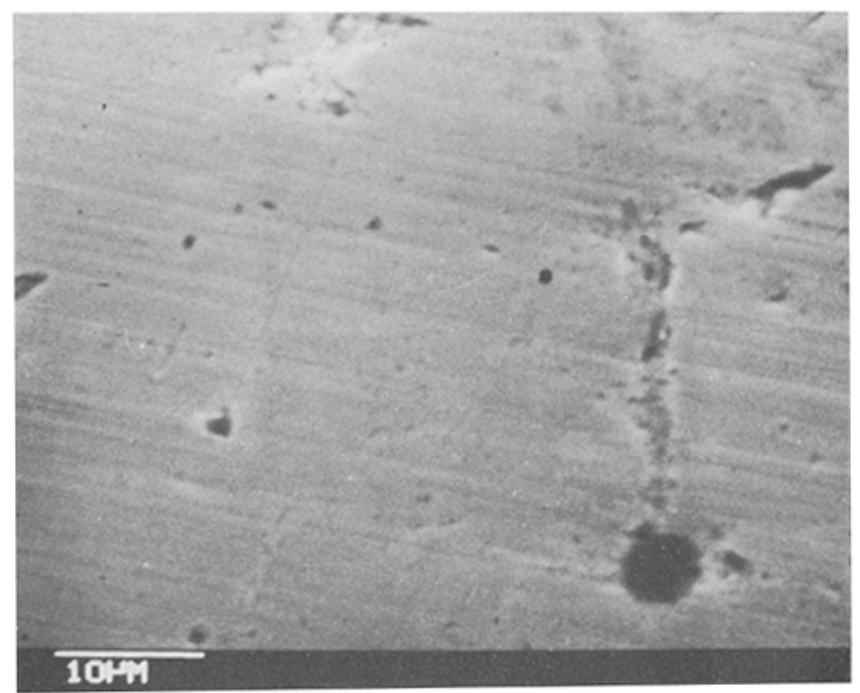

Before contact

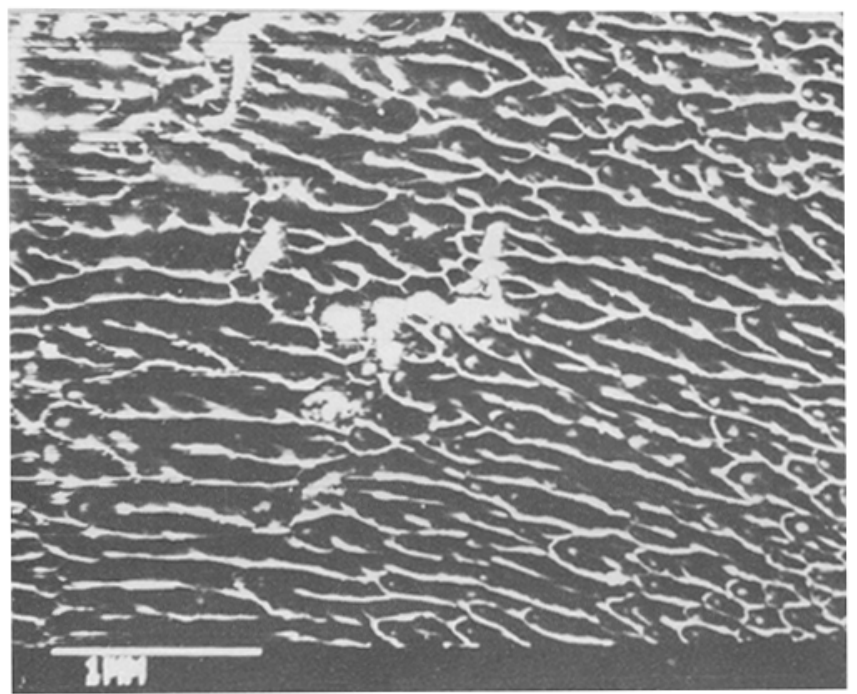

After contact

Figure !1. scantung siecton micrographs of grinding media surface before and after sontact with chalcopyritc.

(iii) Surlace analysis of the chalcopyrite that has been previously interacted with the grinding media revealed the presence of oxy-hydroxide species of iron. Also, there was evidence of a larger iron concentration on the interacted surfaces when compared to a fresh chalcopyrite surface. The decrease in flotability of chalcopyrite after contacting with the ball material could therefore be explained on the basis of the increased iron dissolution from the grinding media and its subsequent adsorption/deposition on the chalcopyrite mineral. 


\section{Acknowledgements}

The authors are thankful to $\mathrm{M} / \mathrm{s}$ Chitradurga Copper Company Limited, Chitradurga, Karnataka for their kind help in supplying ore samples and grinding media. Their sincere gratitude are due to Prof. C N R Rao for encouragement and interest in the work. Thanks are also due to Dr M S Hegde, Mr R Ranga Rao and Mr Raju Mohan for help in carrying out the surface analysis investigation. Thanks are due to Mr R Rajaraman for help with the metallographic study of the ball material.

\section{References}

Adam K and Iwasaki I 1984 Miner. Metall. Process. 181

Learmont M E and Iwasaki I 1984 Miner. Metall. Process. 1136

Nakazawa H and Iwasaki I 1985 Miner. Metall. Process. 2206

Nakazawa H and Iwasaki I 1986 Int. J. Miner. Process. 18203

Natarajan K A and Iwasaki I 1973 Trans. SME (AIME) 25422

Pavlica J J and Iwasaki I 1982 Trans. SME (AIME) 2721885

Perez M 1982 M.Sc. thesis, University of Minnesota

Rey M and Formanek V 1960 in Proc. 5th Int. Min. Proc. Congress. Inst. Mining and Met. London p. 343 Thornton E 1973 in Proc. 5th Annual Meeting of Canadian Mineral Processors, Dept. Energy, Mines and Resources, Ottawa p. 224

Wagner C D 1984 in Practical surface analysis by Auger and X-ray photoelectron spectroscopy (eds) D Briggs and M P Seah (New York: John Wiley) p. 477 